\title{
P 0395 Effect of deworming on hemoglobin concentration in children from 2 to 15 years from the Bengo Province, Angola.
}

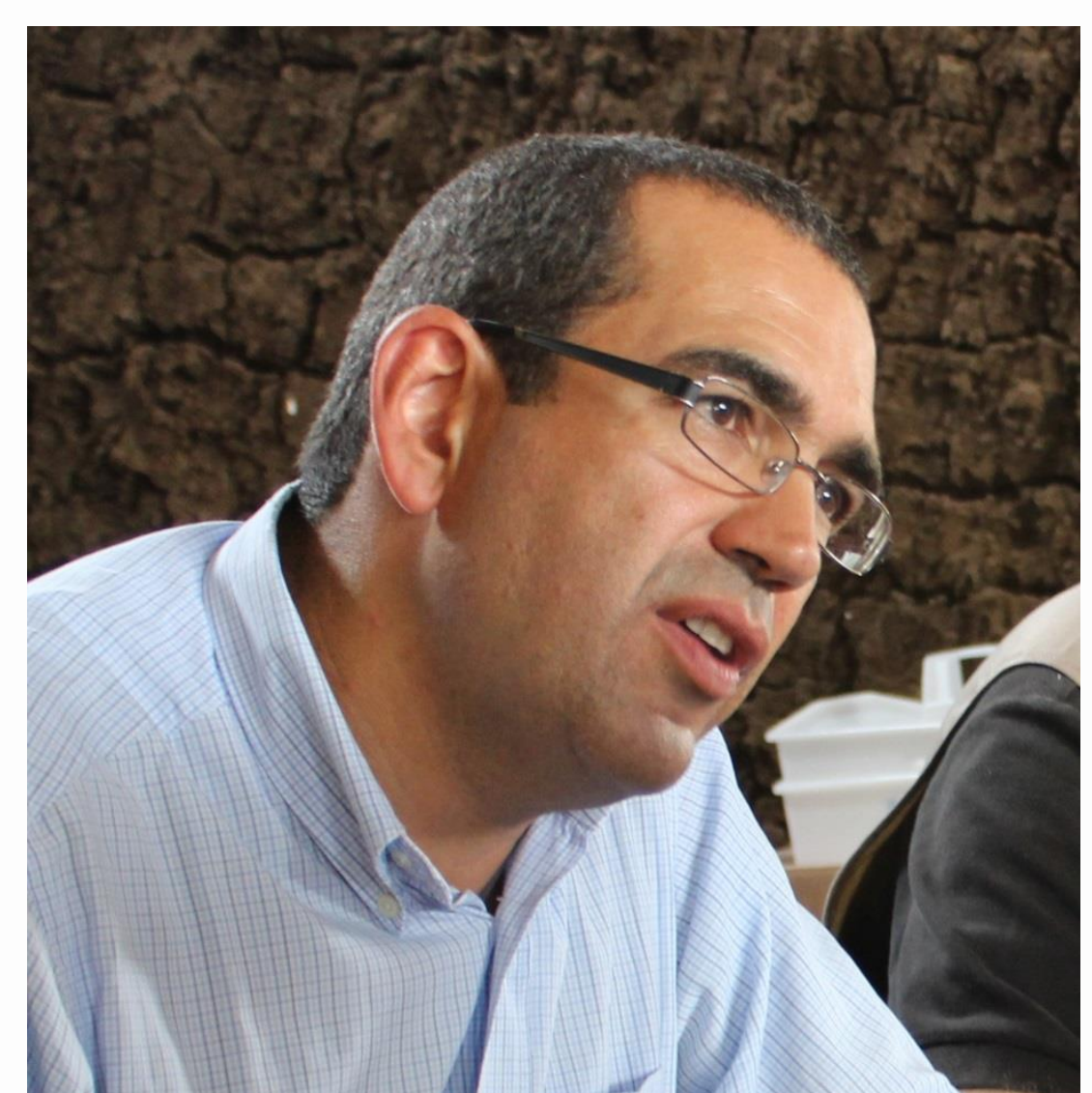

$\underline{\text { Miguel Brito }}^{1,2}$, Manuel Lemos ${ }^{1,3}$, Clara Mirante ${ }^{1}$, Sofia Moura ${ }^{1}$ Carlos Mayer ${ }^{1,4}$

${ }^{1}$ CISA Project-Health Research Centre in Angola, Caxito, Angola; ${ }^{2}$ ESTESL. Lisbon School of Health, Lisbon, Portugal; ${ }^{3}$ Faculty of Medicine, University Agostinho Neto, Luanda , Angola; ${ }^{4}$ Hospital Geral do Bengo, Angola

\section{Introduction}

The most common causes of anemia are micronutrient deficiencies, but other factors may influence namely inflammation, parasitic infections and inherited disorders. One strategy to combat micronutrient deficiencies is supplementation, yet, in zones with high prevalence of Schistosomiasis or Soil Transmitted Helminthes (STH), supplementation could be not sufficient. The aim of this study was to evaluate the effects of deworming, on hemoglobin concentration, in children from 2 to 15 years, from Bengo.

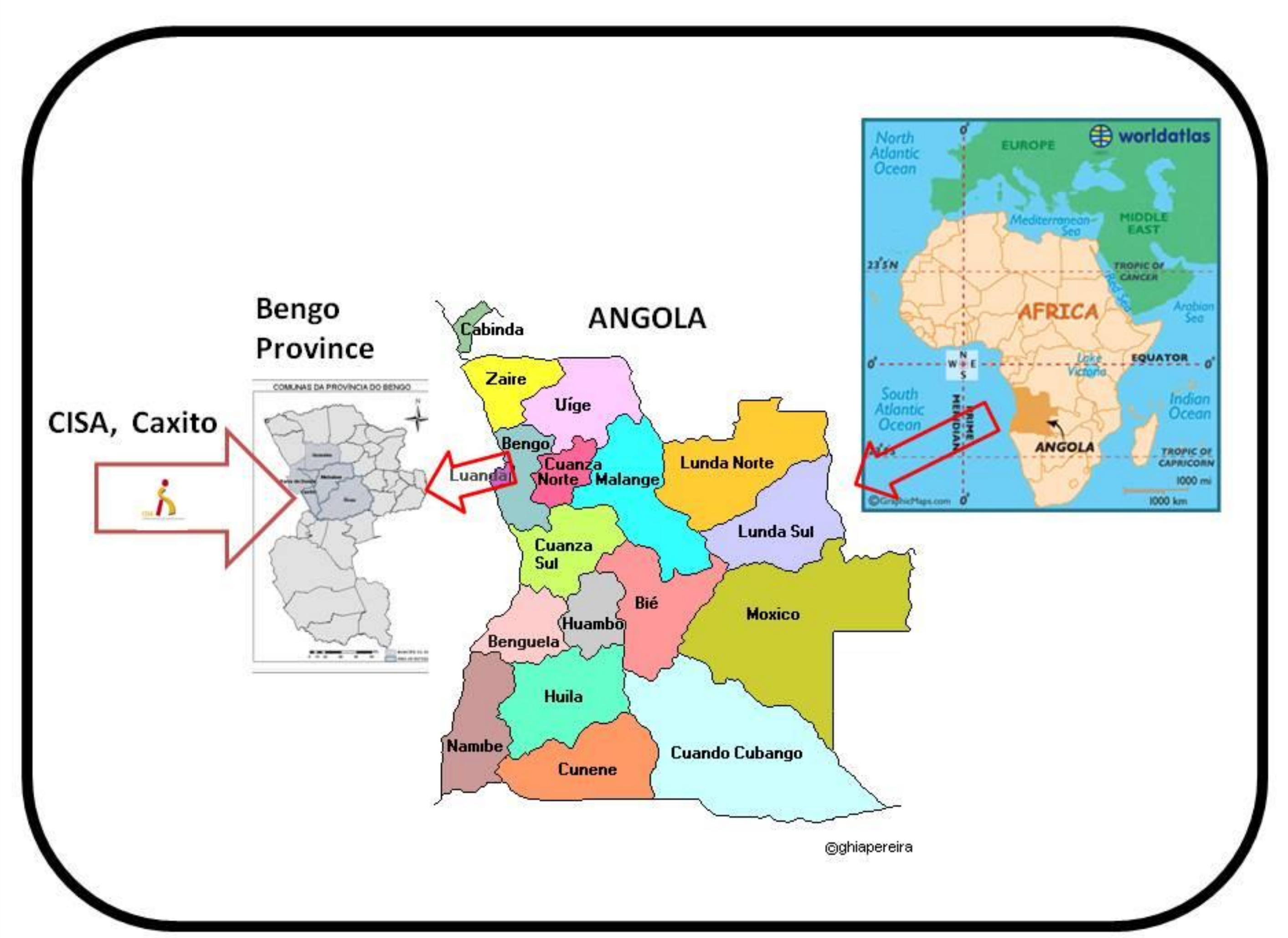

Results

\section{Methodology}

A total of 429 children between 2 to 15 years were involved. Nutritional status and anemia were evaluated. Urine and feces samples were collected for diagnosis of Schistosoma haematobium and STH. Praziquantel $(40 \mathrm{mg} / \mathrm{Kg})$ and Albendazol $(400 \mathrm{mg})$ were administrated. All parameters were determined at baseline and after 6 months.

This study is being conducted in the Project CISA, located $60 \mathrm{~km}$ from Luanda, in the town of Caxito, an urban centre in Dande Municipality, in Bengo Province, and home to an estimated population of 250,000. Dande Municipality, a rural area defined as the Project's priority intervention area, has an estimated average population of 68,000 inhabitants.

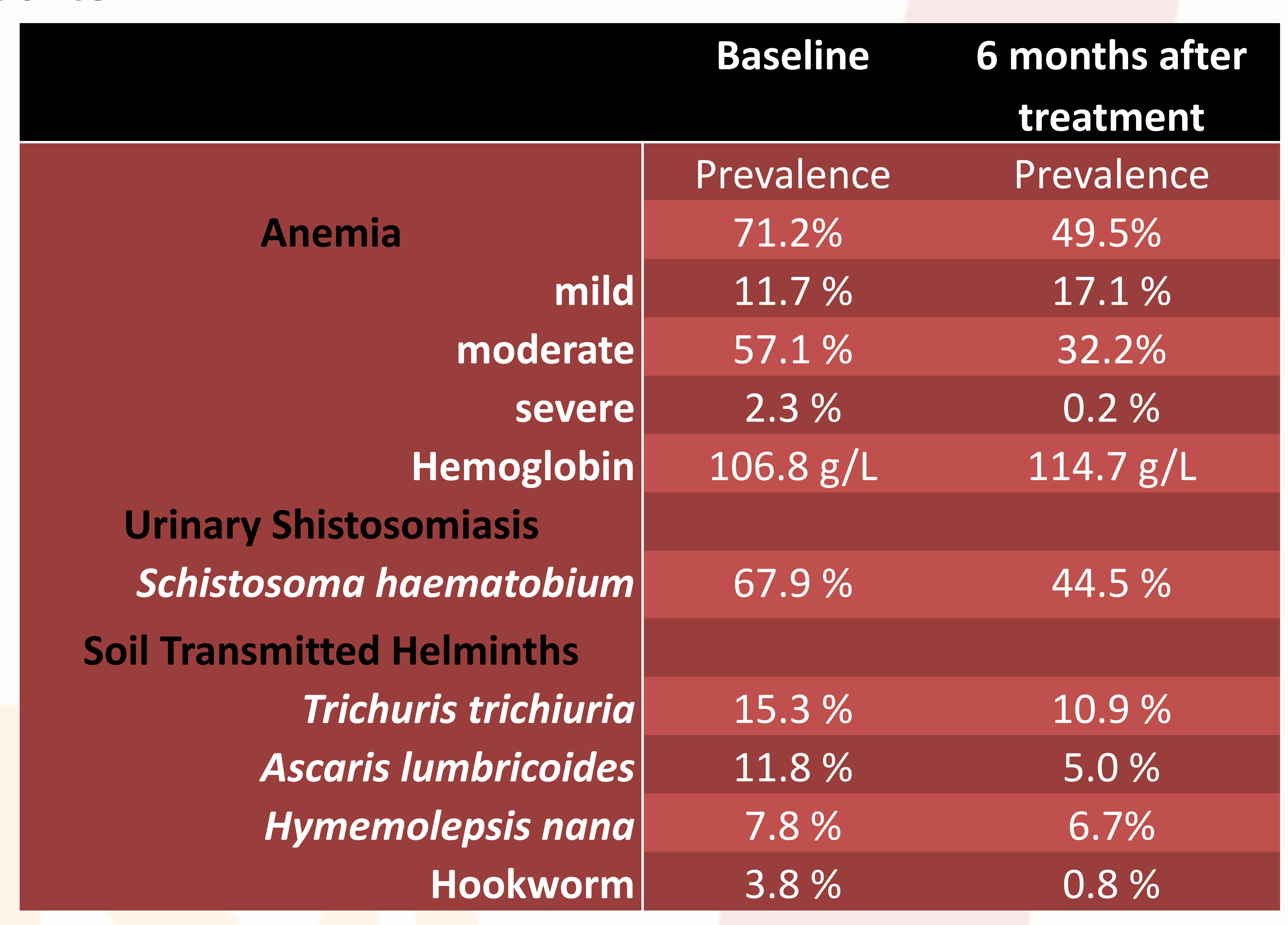

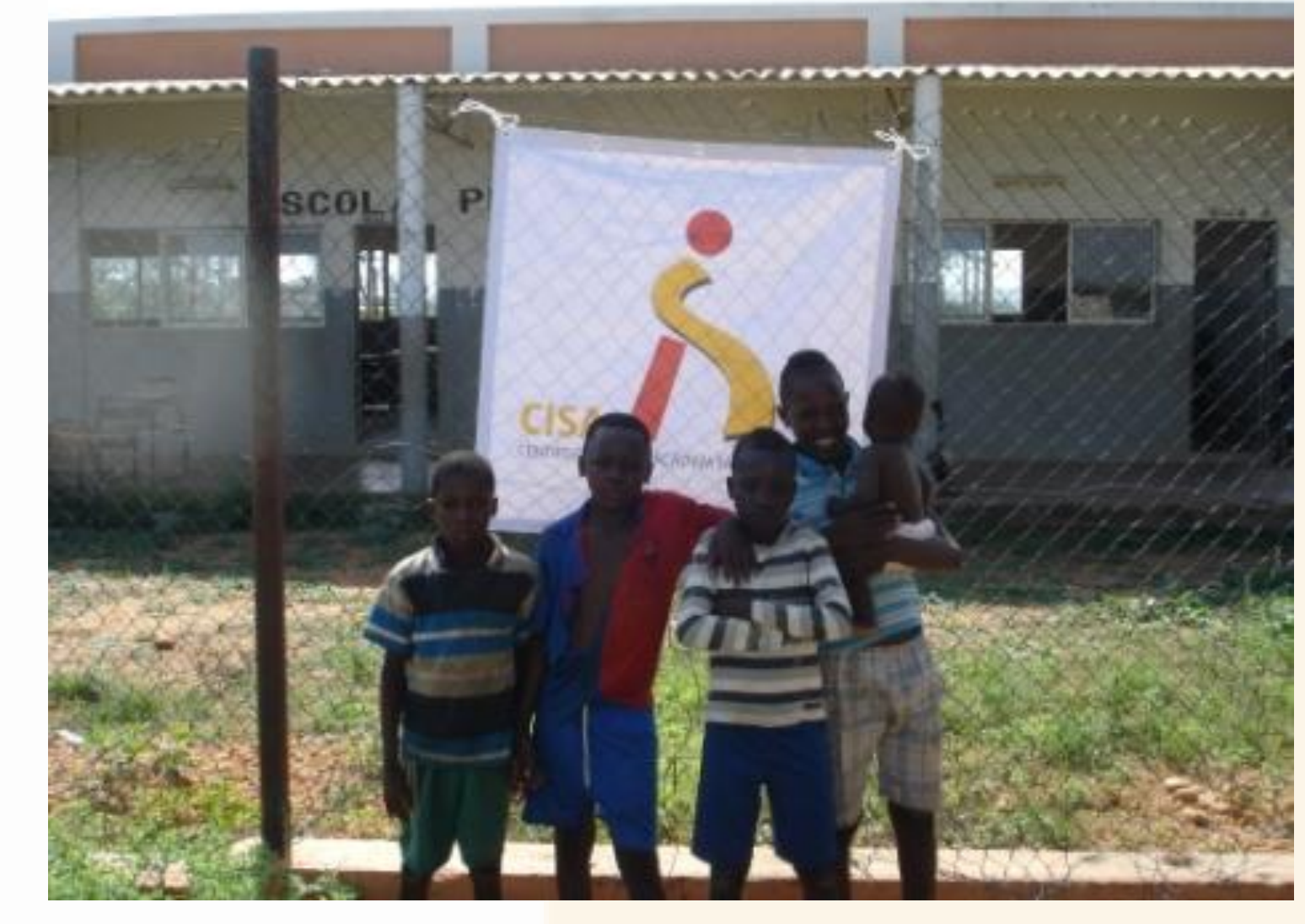

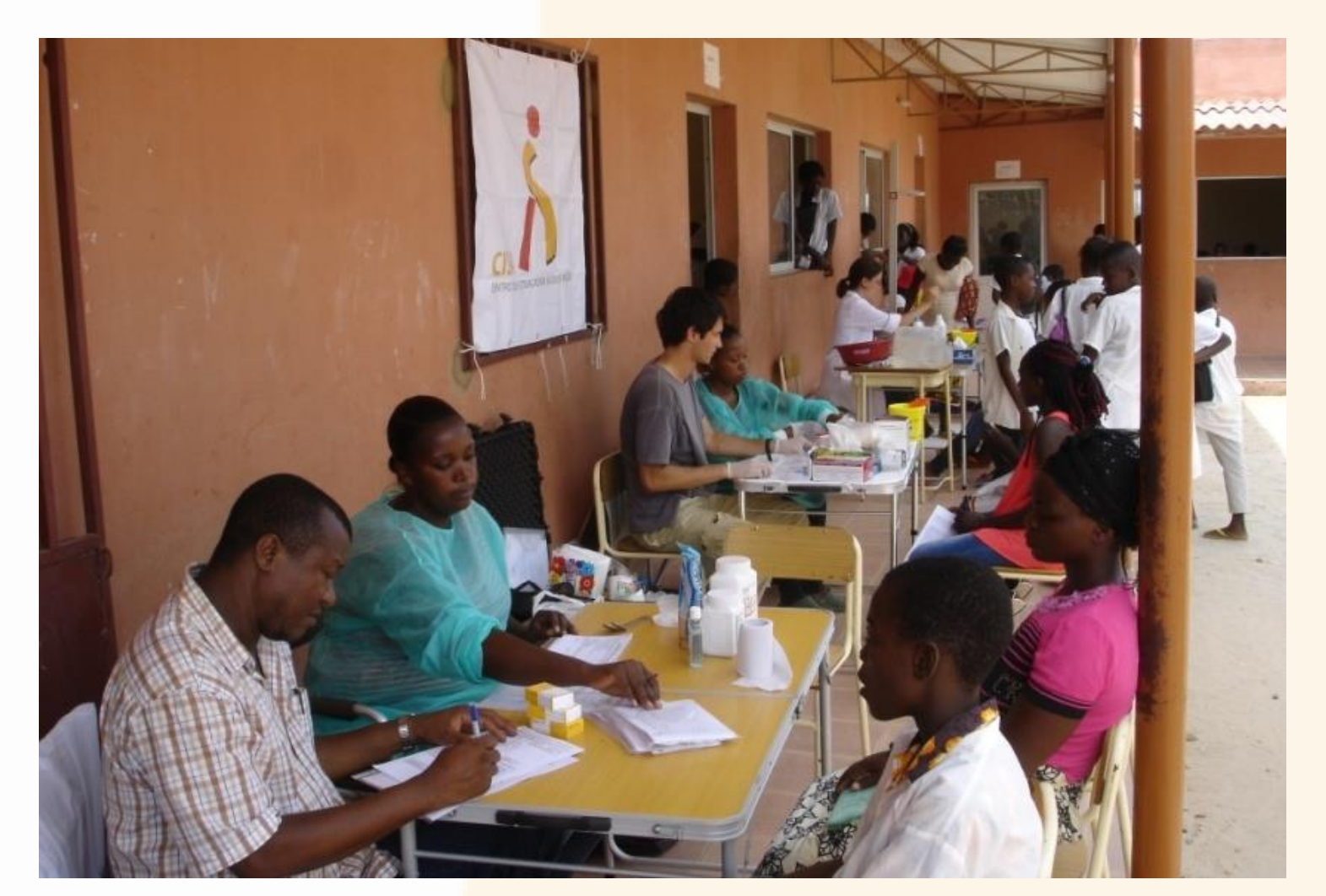

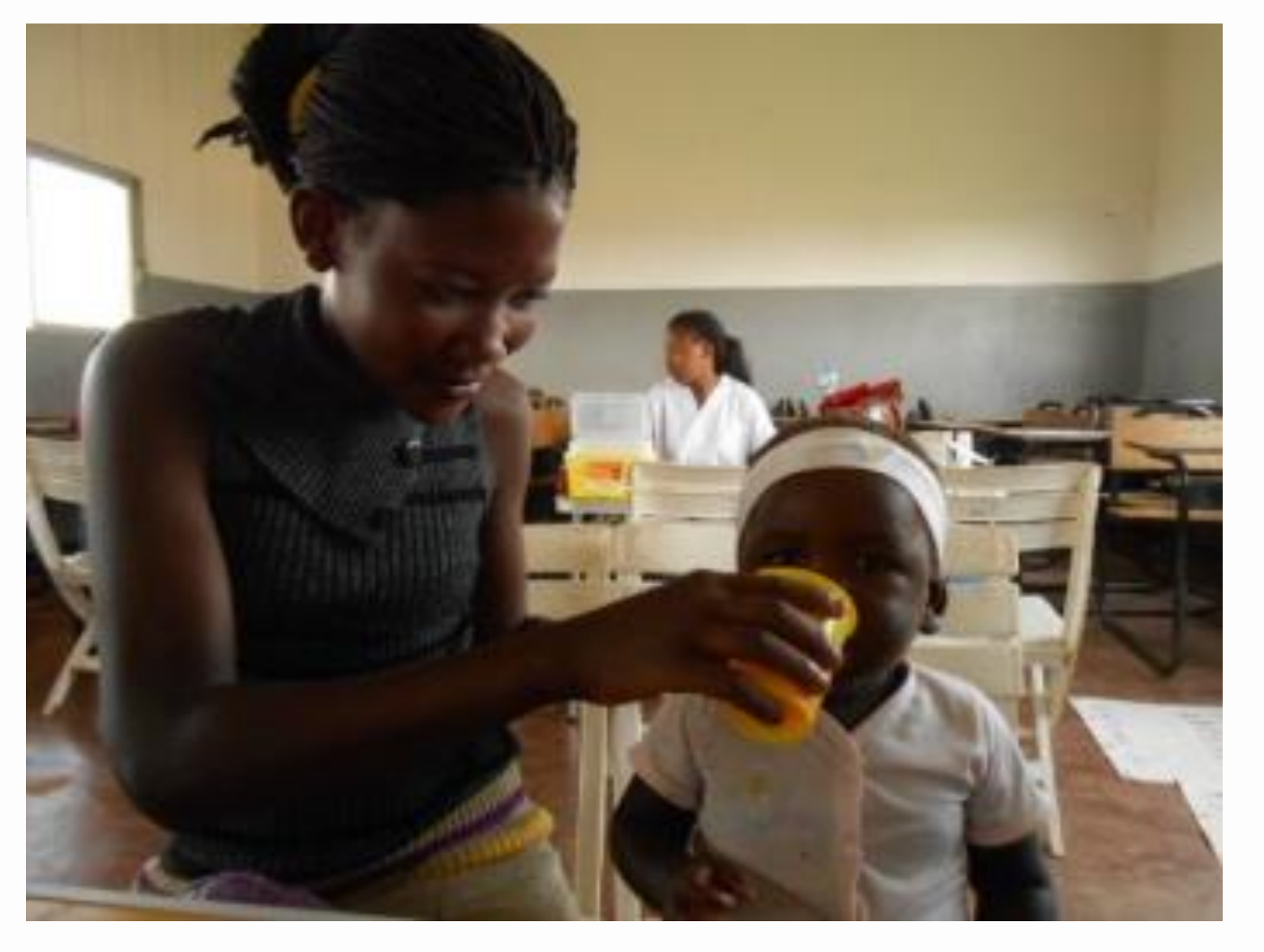

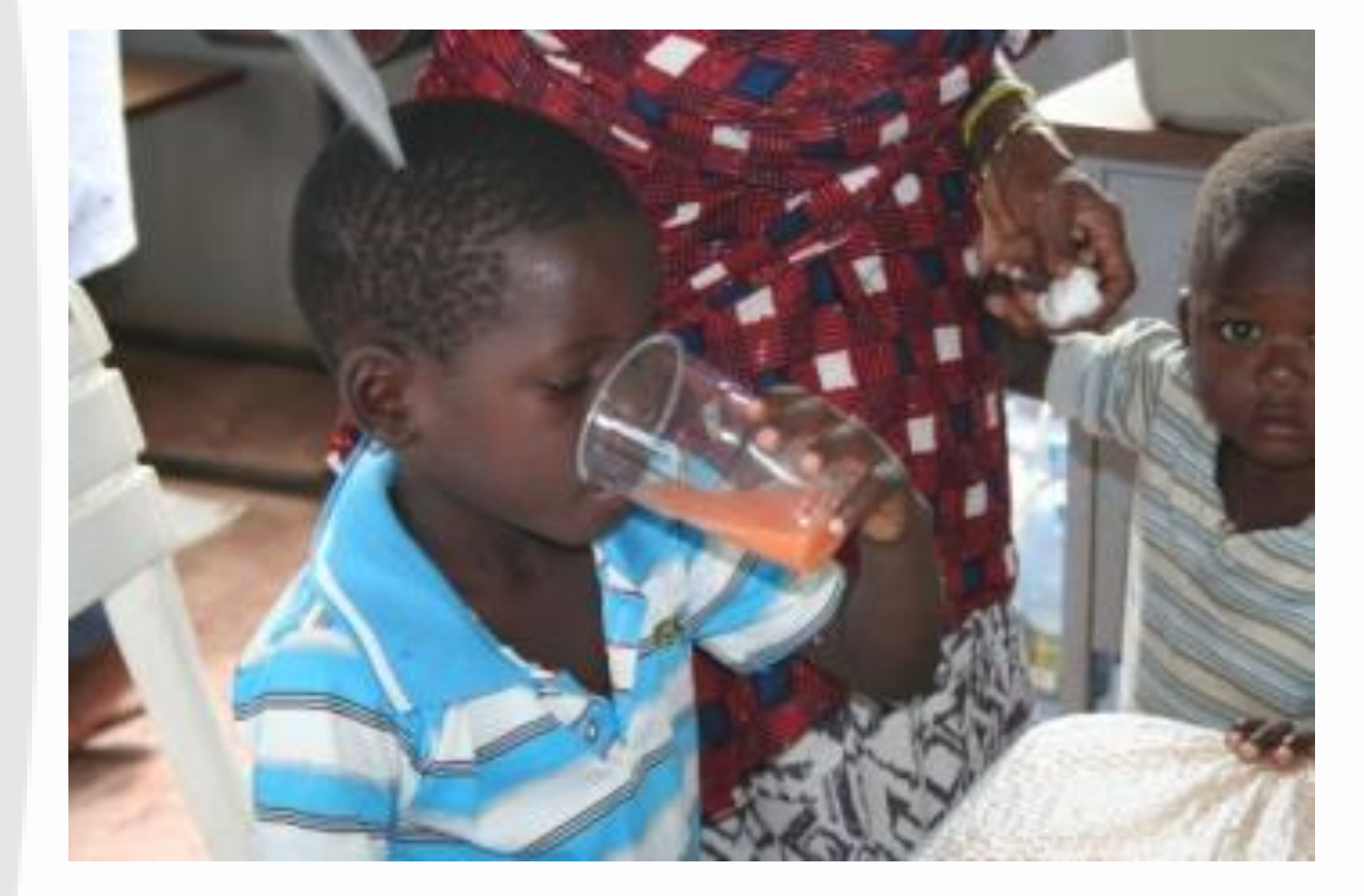

\section{Conclusions}

These results confirm the benefit of deworming on hemoglobin concentration, even with a single intervention. However it should be clear that integrated intervention aiming nutritional education water treatment, hygiene and sanitation are needed to reduce micronutrient deficiency.

Contacts PROJECT CISA Hospital Geral do Bengo, Caxito, Angola, info@cisacaxito.org, www.cisacaxito.org

Research Coordinator, Miguel Brito, PhD, miguel.brito@cisacaxito.org

Patrons and funding entities

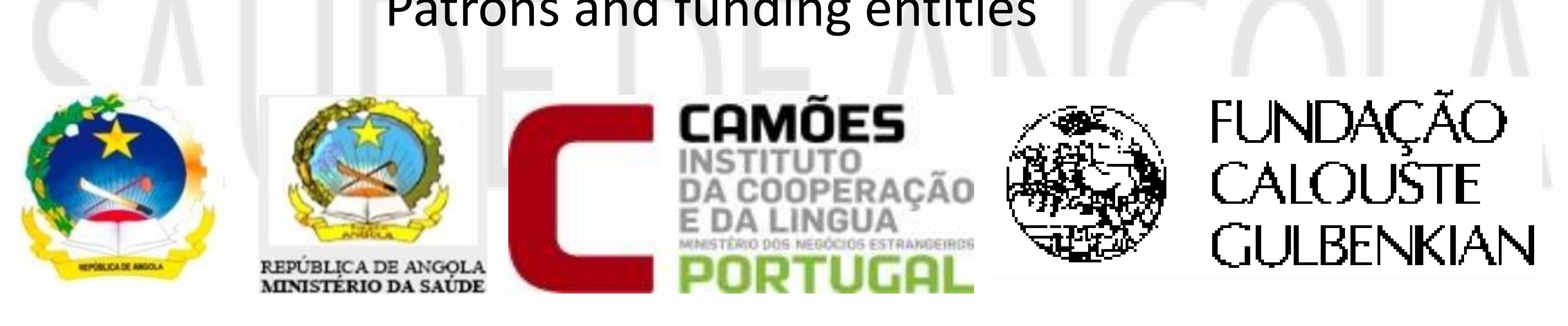

